Original Research Paper

\title{
Determination of Breeding Seasonality in Rusa Deer (Rusa timorensis) Stags via Serum Testosterone Profiling
}

\author{
${ }^{1}$ Wan Nor Fitri Wan Jaafar, ${ }^{1,6}$ Abd Wahid Haron, ${ }^{1}$ Rosnina Hj Yusoff, \\ ${ }^{1,2}$ Faez Firdaus Jesse Abdullah, ${ }^{7}$ Siti Aimi Sarah Zainal Abidin, ${ }^{3}$ Mohd. Azmi Mohd Lila, \\ ${ }^{1}$ Azlan Che' Amat, ${ }^{4}$ Muhammad Azrolharith Rashid and ${ }^{5}$ Mohamed Ariff Omar \\ ${ }^{I}$ Department of Veterinary Clinical Studies, Faculty of Veterinary Medicine, \\ ${ }^{2}$ Research Centre for Ruminant Disease, \\ ${ }^{3}$ Department of Veterinary Pathology and Microbiology, Faculty of Veterinary Medicine, \\ ${ }^{4}$ Small Ruminant Unit, Taman Pertanian Universiti, Ladang 16, \\ ${ }^{5}$ Department of Pre-Clinical Science, \\ ${ }^{6}$ Wildlife Research Centre of Excellent, \\ Universiti Putra Malaysia, 43400 UPM Serdang, Selangor, Malaysia \\ ${ }^{7}$ Faculty of Applied Science, Universiti Teknologi Mara (UiTM), 40450 Shah Alam, Selangor, Malaysia
}

Article history
Received: 06-12-2016
Revised: 04-03-2017
Accepted: 09-03-2017
Corresponding Author:
Abd Wahid Haron
Department of Veterinary
Clinical Studies, Faculty of
Veterinary Medicine, Universiti
Putra Malaysia, 43400 UPM
Serdang, Selangor, Malaysia
Tel: +603-8609 3941
Email: wahidh@upm.edu.my

\section{Introduction}

The essence of breeding seasonality in many species of deer is the scarcity and availability of resources such as feed. Due to the limited resources, animals need to take advantage of the environmental changes-to raise young's during period of good quality pasture or fruits abundance (O’Brien, 1993). Reproductive fitness can be measured as the ability of the species to reproduce, sustain, survive and thrive. In order to do this, mammals had developed certain cues from the environment such as

\begin{abstract}
Breeding seasonality in mammals is influenced by the environmental changes and the endocrine response of the animals to that changes. Comprehension in breeding seasonality enables better reproductive management consequently maximizing the reproductive potential of the stags. Despite that, the study in breeding seasonality in Rusa deer (Rusa timorensis) is still scarce. Five healthy and matured stags were selected for this experiment. Semen were collected using electroejaculator at a monthly interval from April to September 2012. Semen motility is determined using a percentage. Meteorological data were obtained from the nearest weather station located in Petaling Jaya. Serum was utilized for the radioimmunoassay determination of serum testosterone profile. The warmest condition was in June and it's coolest in November of 2012. There was a strong, positive correlation between testosterone concentration and general motility $(p<0.05)$ with a correlation coefficient, $r_{s}$ $=0.943$. Meteorological data alone; temperature, relative humidity and rainfall are insufficient to determine the breeding seasonality in Rusa deer, bearing no significant correlation with serum testosterone concentration and sperm motility. Rusa deer stags is reproductively active from April to July, low in August and starts to rise again in September. Therefore, this study demonstrates that breeding seasonality in Rusa deer stags can be determined via serum testosterone profiling.
\end{abstract}

Keywords: Rusa Deer, Stags, Breeding, Seasonality, Meteorology, Testosterone, Semen Evaluation responding to photoperiod, temperature, rainfall and food availability (Bronson, 2009). Deer too was found to be able to receive early signals to anticipate to this environmental changes (Moyes et al., 2011). However, there is a scarcity of study in search of the indicators responsible for Rusa deer stags seasonality.

Rusa deer (Rusa timorensis) is not a local species of deer from Malaysia, but it is native to Indonesia (Hedges et al., 2015). Deer industry in Malaysia started by farming for venison and as a result Rusa deer is the most abundant species of deer farmed in Malaysia 
(Vidyadaran et al., 1993). The only native species of deer in Malaysia is the Sambar deer (Rusa unicolor) and the history of deer farming in Malaysia was in response to the dwindling population of its native kind due to overhunting (Mohd-Khan, 1967). Moreover, the current population of Sambar deer in Peninsular Malaysia was heading towards extinction (Kawanishi et al., 2014). Therefore, studying reproductive seasonality of Rusa deer is important because it could also be a model for wild and endangered species of deer such as the Sambar deer in Peninsular Malaysia. This study has an extended application to overcome challenges and filling the knowledge gap of deer reproductive biology.

Malaysia is located in the tropical equatorial region. Compared with other parts of the world, the tropics has the richest number of biodiversity than other region. On the contrary, the knowledge of reproductive biology of the animals and deer in the tropics which falls under the taxa prone to extinction largely remain unknown (Asher, 2011; O'Brien, 1993). Understanding the basic reproductive biology of deer and the application of knowledge to the breeding seasonality is one of the few first crucial step to Assisted Reproductive Technology (ART) to improve the genetic of the species. This importance was demonstrated in the studies of other species of important mammals in Malaysia (Amare et al., 2009; Iswadi et al., 2012; Sarsaifi et al., 2015; Wahid et al., 2000), however not much information is available in Rusa deer (Rusa timorensis) until recently (Mahre et al., 2014). Rusa deer is regarded both as a valuable economic source and an important source of food security to the nation. This potential is yet to be fully utilized as Rusa deer in Malaysia are only bred completely by natural mating. The million dollars industry could have benefited more from genetics advancement through ART (Pintus and Ros-Santaella, 2014), thus, it is proposed in this study that the serum testosterone concentration be investigated to determine the breeding seasonality of Rusa deer stags especially in the tropics.

Determining the reproductive stages and the breeding season of stags are beneficial for many purposes. Breeding and feeding management, assisted reproductive technology and breeding soundness evaluation all require a degree of information on the reproductive seasonality of the species. The breeding seasonality in Rusa deer varied from different locations (Mourik and Stelmasiak, 1990). On the surface, reproductive physiology of a Rusa deer in tropical region could be regarded as seasonal as compared to the temperate species of deer like Reindeer, Rangifer tarandus. However, there are reproductive trends based on the fawning period, backdating the rutting season from March to April (Zakaria et al., 2016). This is further supported when the Rusa deer are managed in subtropical region and exhibiting strong seasonality
(Sinclair and Woodford, 2000). Rusa deer was found to be a long-day breeder as opposed to other boreal species of deer (Mourik and Stelmasiak, 1990; Zerbe et al., 2012). To date, there is no study in Rusa deer that utilize testosterone concentration that specifically focuses on reproductive ability. Meanwhile Rusa deer female reproductive biology had been described recently (Mahre et al., 2016; 2012; 2015a; 2015b), while the dearth in the study of Rusa deer stags seasonality remains. The objective of this paper is to describe the serum concentration profile of Rusa deer.

Breeding seasonality in Rusa deer in Malaysia is unknown. Hence this study aims to profile serum testosterone concentration, to relate with sperm motility and meteorological data to reflect on the reproductive seasonality of Rusa deer stags.

\section{Materials and Methods}

\section{Ethical Consideration}

This research was approved by Animal Care and Use Ethics Committee, Universiti Putra Malaysia (Reference Number: UPM/FPV/PS/3.2.1.551/AUP-R141).

\section{Animals and Management}

Five healthy and matured stags were selected for this experiment. The deer were maintained by Small Ruminant Unit, Taman Pertanian Universiti (TPU), Universiti Putra Malaysia (UPM). The stags were all matured based on birth records and aged at least 3 years and above. Average live body weight of the stags were $79 \pm 2.15 \mathrm{~kg}$. The stags were housed together with hinds in a paddock and managed as a herd. The animals were allowed to graze on guinea grass and supplemented with palm kernel cake estimated at $800 \mathrm{~g}$ per animal daily. Water were provided ad libitum.

\section{Semen Collection and Evaluation}

Semen were collected using electroejaculator at a monthly interval from each individual from April to September 2012. Semen collecting procedure was conducted from an established protocol in wildlife species (Wahid et al., 2000). Semen were collected using electroejaculator (P-T Electronics, Boring, USA). Semen parameters recorded were sperm motility based on a standard described in Rusa deer recently (Mahre et al., 2014). Sperm motility were obtained from $10 \mu \mathrm{L}$ of neat semen, observed under $10 \times$ magnification and estimated for general motility percentage. Semen evaluation were done by two experienced laboratory technicians independently immediately once the semen were collected and the mean from the two readings were recorded to obtain a better representative of the sperm motility percentage estimation. 


\section{Meteorological Data}

Daily meteorological data obtained were from Malaysian Meteorological Department. Data were obtained from the nearest weather station from the farm which was located in Petaling Jaya; $\left(3^{\circ} 06^{\prime} 07^{\prime \prime} \mathrm{N}, 101^{\circ}\right.$ $38^{\prime} 42^{\prime \prime}$ E). Meteorological data processed were records of daily rainfall amount $(\mathrm{mm})$, records of $24 \mathrm{~h}$ mean temperature $\left({ }^{\circ} \mathrm{C}\right)$ and records of $24 \mathrm{~h}$ mean relative humidity (\%). Daily data were obtained from April to November 2012.

\section{Testosterone Radioimmunoassay Analysis}

Serum was collected from all 5 stags from April to November 2012 at a weekly interval. Blood was collected intravenously via the jugular vein and left to clot at room temperature for $30 \mathrm{~min}$ before being placed in a $4^{\circ} \mathrm{C}$ cold box. Serum was separated by centrifugation at $5,000 \mathrm{G}$ for $5 \mathrm{~min}$, then immediately kept in $-80^{\circ} \mathrm{C}$ freezer before being analyzed in batches. Testosterone concentrations in plasma were quantified by using a commercially available Radioimmunoassay (RIA) kit (Immunotech $®$, France). Procedures for radioimmunoassay protocol are followed as provided by the manufacturer. Count Per Minute (CPM) were read using a gamma counter. The assay quality control containing known testosterone concentrations were included in the beginning and at the end of each assay. Intra-assay coefficient of variation were less than $10 \%$ with $0.99 \mathrm{R}$-squared value. The testosterone assay specificity was $100 \%$ (testosterone) and sensitivity was $0.02 \mathrm{ng} \mathrm{mL} \mathrm{m}^{-1}$. Serum monthly mean concentration were obtained based on pooled monthly individuals reading and were subjected to statistical analysis.

\section{Statistical Analysis}

Serum concentration level, meteorological data, semen characteristics were subjected to analysis using the statistical package IBM SPSS Statistics 20, values were reported as mean \pm SEM. Analysis of variance followed by Tukey HSD post-hoc test and T-test was used to identify significant difference between testosterone concentrations, semen characteristics and between the meteorological data in each months at the significant level of $p<0.05$. Spearman's Rho Test was used to determine correlation between parameters at $p<0.01$ significant level.

\section{Results}

\section{Semen Collection and Evaluation}

There was no significant difference between different months and individuals collected for sperm motility. Semen motility is highest in July at $86 \pm 5 \%$ and very poor in August with zero sperm motility. The results of sperm motility of Rusa deer were summarized (Table 1).
Table 1. Sperm motility (mean \pm SEM) of Rusa deer from April to September

\begin{tabular}{ll}
\hline Month & Sperm motility \% \\
\hline April & $70 \pm 20$ \\
May & $83 \pm 6$ \\
June & $74 \pm 9$ \\
July & $86 \pm 5$ \\
August & $0 \pm 0$ \\
September & $57 \pm 23$ \\
\hline
\end{tabular}

Table 2. Monthly (mean \pm SEM) temperature, relative humidity and rainfall amount from April to November

\begin{tabular}{llll}
\hline Month & $\begin{array}{l}\text { Temperature } \\
\left({ }^{\circ} \mathrm{C}\right)\end{array}$ & $\begin{array}{l}\text { Relative } \\
\text { humidity }(\%)\end{array}$ & Rainfall $(\mathrm{mm})$ \\
\hline April & $28.75 \pm 0.18^{\mathrm{c}, \mathrm{d}}$ & $78.82 \pm 0.90^{\mathrm{c}, \mathrm{d}}$ & $7.49 \pm 1.92^{\mathrm{a}, \mathrm{b}}$ \\
May & $29.05 \pm 0.18^{\mathrm{c}, \mathrm{d}}$ & $76.71 \pm 0.92^{\mathrm{b}, \mathrm{c}, \mathrm{d}}$ & $10.09 \pm 4.56^{\mathrm{a}, \mathrm{b}, \mathrm{c}}$ \\
June & $29.46 \pm 0.17^{\mathrm{d}}$ & $69.25 \pm 0.91^{\mathrm{a}}$ & $0.76 \pm 0.38^{\mathrm{a}}$ \\
July & $28.29 \pm 0.19^{\mathrm{b}, \mathrm{c}}$ & $73.46 \pm 1.23^{\mathrm{a}, \mathrm{b}}$ & $5.30 \pm 2.15^{\mathrm{a}, \mathrm{b}}$ \\
August & $28.34 \pm 0.19^{\mathrm{b}, \mathrm{c}}$ & $74.05 \pm 1.20^{\mathrm{b}}$ & $2.97 \pm 1.05^{\mathrm{a}, \mathrm{b}}$ \\
September & $28.36 \pm 0.18^{\mathrm{b}, \mathrm{c}}$ & $75.35 \pm 0.90^{\mathrm{b}, \mathrm{c}}$ & $4.70 \pm 1.72^{\mathrm{a}, \mathrm{b}}$ \\
October & $27.7 \pm 0.21^{\mathrm{a}, \mathrm{b}}$ & $79.87 \pm 1.22^{\mathrm{d}, \mathrm{e}}$ & $14.81 \pm 3.67^{\mathrm{b}, \mathrm{c}}$ \\
November & $27.25 \pm 0.97^{\mathrm{a}}$ & $83.71 \pm 0.77^{\mathrm{e}}$ & $22.80 \pm 4.93^{\mathrm{c}}$ \\
Total mean & $28.40 \pm 1.20$ & $76.40 \pm 0.44$ & $76.40 \pm 6.95$ \\
\hline
\end{tabular}

Different superscripts between columns indicate a significant difference between means at $p<0.05$

Table 3. Rusa deer monthly serum testosterone concentration

\begin{tabular}{ll}
\hline Month & $\begin{array}{l}\text { Testosterone } \\
\text { concentration }(\mathrm{ng} / \mathrm{mL})\end{array}$ \\
\hline April & $0.2 \pm 0.04^{\mathrm{a}}$ \\
May & $0.38 \pm 0.12^{\mathrm{a}}$ \\
June & $0.22 \pm 0.24^{\mathrm{a}}$ \\
July & $1.41 \pm 0.50^{\mathrm{b}}$ \\
August & $0.02 \pm 0.14^{\mathrm{a}}$ \\
September & $0.05 \pm 0.22^{\mathrm{a}}$ \\
October & $0.06 \pm 0.27^{\mathrm{a}}$ \\
November & $0.17 \pm 0.06^{\mathrm{a}}$
\end{tabular}

Means within columns with different superscripts significantly differ at $p<0.05$

\section{Meteorological Data}

There was statistically significant difference meteorological parameters between different months. Monthly mean of daily records of $24 \mathrm{~h}$ mean temperature $\left({ }^{\circ} \mathrm{C}\right)$ and records of $24 \mathrm{~h}$ mean relative humidity $(\%)$ and rainfall amount $(\mathrm{mm})$ were summarized (Table 2). The coolest, most humid and most rainfall was significant in November while it is significantly warmer in June.

\section{Testosterone Radioimmunoassay Analysis}

There was significant difference $(p<0.05)$ in testosterone level between different months. Post-hoc test further reveals that the serum testosterone concentration in the month of July is significantly different $(p<0.05)$ from the rest of the months. Weekly and monthly testosterone profile of Rusa deer is described (Fig. 1). The detailed monthly serum concentration of Rusa deer was depicted (Table 3). 


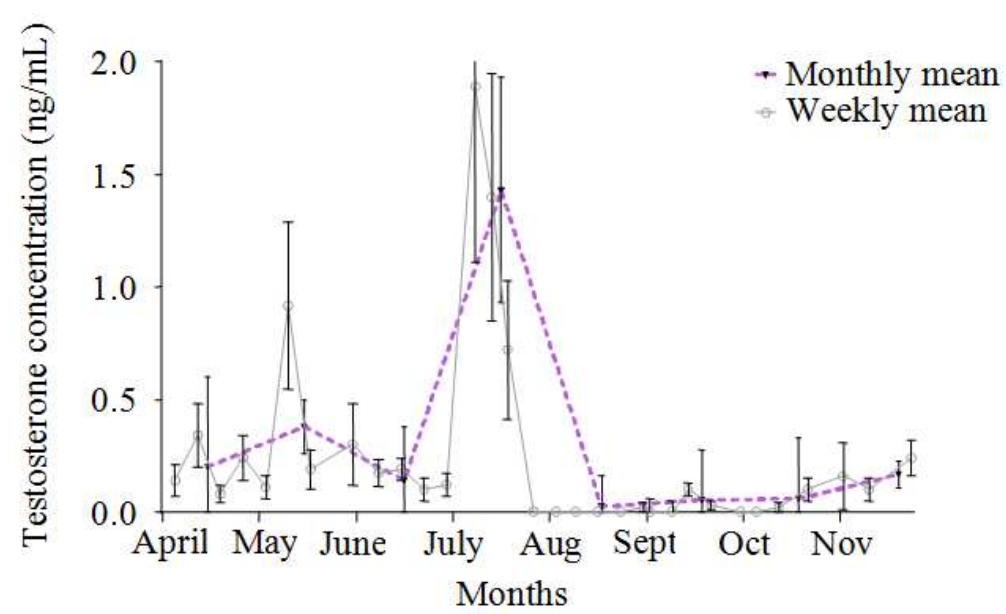

Fig. 1. Rusa deer stags weekly and monthly testosterone profile

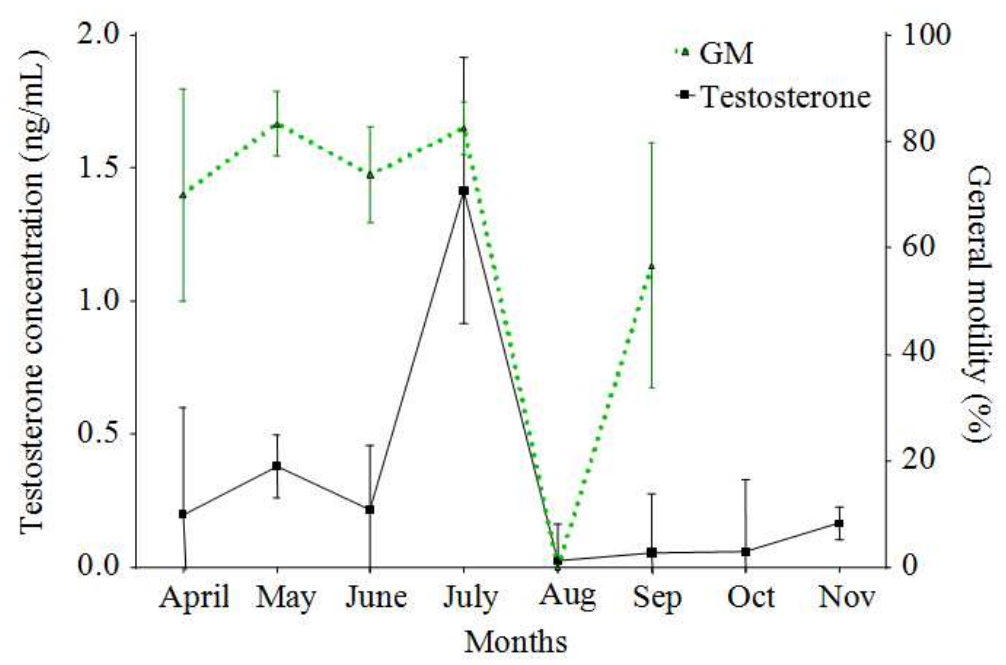

Fig. 2. Rusa deer stags monthly testosterone profile and sperm general motility percent

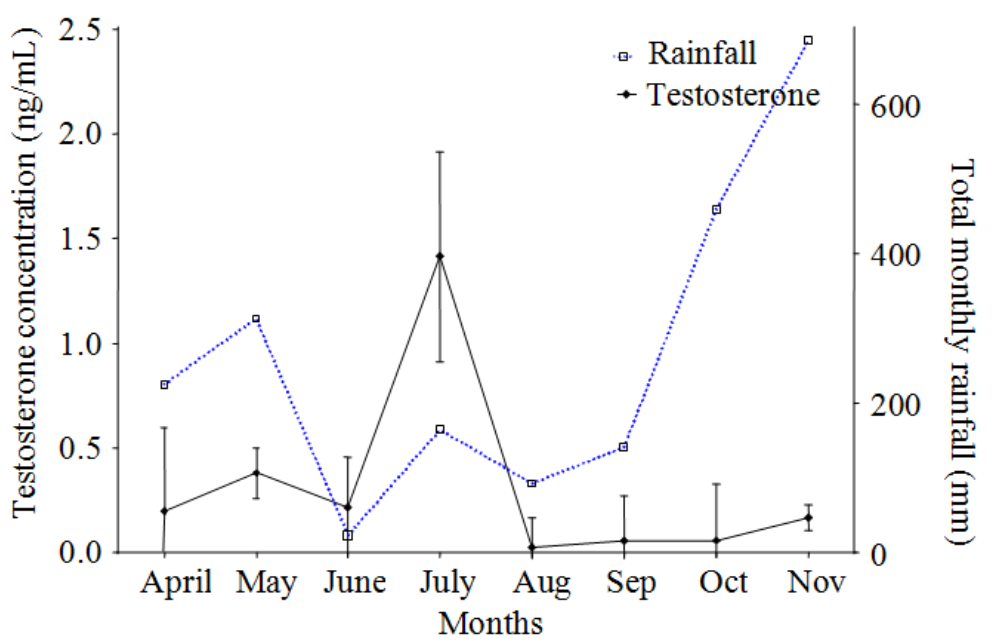

Fig. 3. Rusa deer stags monthly testosterone profile and total monthly rainfall (mm) 


\section{Statistical Analysis}

There was a strong, positive correlation between testosterone concentration and sperm motility $(p<0.05)$ with a correlation coefficient, $r_{s}=0.943$. This relationship is illustrated in the graph (Fig. 2).

There was no significant different between testosterone concentration and sperm motility when compared with meteorological data. No significant correlation between serum testosterone concentration of Rusa deer and meteorological data even when compared daily, weekly, monthly and between breeding and off season. However, a graph between testosterone concentration and total rainfall is portrayed to show the trend that rainfall plays to testosterone concentration (Fig. 3).

\section{Discussion}

For long human have been intrigued with breeding seasonality in animals and there had been various indicators found to be related with breeding seasonality. Antler growth and stages plays a dynamic role in deer and is driven by testosterone (Savanth and Saseendran, 2012). Deer is unique to having antler which grow once a year just for the breeding ritual purposes and then the antler is casted towards the end of breeding season when it is no longer in use. Deer behavior can also be used to identify the beginning of rutting season, the period which stags compete to mate with hinds (Samsudewa and Capitan, 2013). However this two parameters require active participation in observation and proper recording system and is not always practical in determining the actual seasonality. Meanwhile, series of at least two testosterone concentration in stags fit into an established serum testosterone profile can provide a peak into the male reproductive physiology. Serum testosterone profile is therefore a suitable parameter that can serves both as a reliable indicator and predictor of breeding stage and semen motility in Rusa deer stags.

During the breeding ritual or rutting season, the stags compete for mating right and the hormone that heavily drives the rutting season is testosterone. Rutting season is antler dependent, as the antler was theorized to have evolved as a tool for weapon during sparring session. Naturally selection during mating will also favor for the best shape and size of 'weapon' and this traits is passed down to the progeny through mating. This is not as straightforward as antler as either for weapon or display, the process involves a complex mechanism that interchange between the behaviour, physiology and mostly androgen of the stags. Social behaviour of the animal based on ranking was found to have an effect on the testosterone concentration giving rise to antler size; the higher ranking animal experiencing enhanced antler growth (Bartos, 2012). Other study supporting the role of antler growth from testosterone in experimental administration of exogenous androgens in castrated, free martin and normal female (Li et al., 2003). Meanwhile another study highlight the function of cortisol and its consistency as opposed to testosterone in determining the rank of male in a herd (Pavitt et al., 2015). However, the same study observed that testosterone peak during the breeding season (Pavitt et al., 2015). This study conduct testosterone concentration analysis in accordance with sperm motility to investigate the direct effect of testosterone to reproductive ability. Similar method was established in dogs (Albrizio et al., 2013). Hence, rise in testosterone concentration in stags must be made with all this factors under consideration; (1) social dynamics, (2) antler growth stages, (3) reproductive effort and (4) reproductive stage.

Stags exhibit the rutting behaviour due to the direct incentive and response from the hinds. This was demonstrated by a study that stags will only develop a complete sexual behavior in presence of hinds (Villagrán and Ungerfeld, 2013). Hinds developed seasonality in response to favor the season when body condition of the hinds is at its best to conceive and to raise the fawn (Asher, 2011). However, some studies based on length of fawning period argue the concept of breeding seasonality in Rusa deer (Asher, 2011; Zerbe et al., 2012). This is due to the long fawning period which echoes the weak seasonality in the species. In contrast, other study of deer in the tropics suggested otherwise due to the apparent peak fawning from certain months (Zakaria et al., 2016). Based on testosterone profile of Rusa deer stags, the two peaks of testosterone profile suggest a rise in reproductive activity over the period of three months-May to July. The peak of testosterone in May is probably the point of return before it settle at lower concentration and peak again in July before it finally quiescent in August. In actuality, the real breeding season based on backdating of the fawning records may occur earlier perhaps in March to April and prolonged before one last push in July. The reason for low crests and minimums creating undulating pattern of testosterone profile in April could be due to the number of hinds coming to heat. When there is more hinds available, then the stags do not need to compete so much as to breed, but to maintain the balance between mating and rutting. It is advantageous to be moderate in time which the stags need to serve high number of hinds. This is different in the case of hinds that came to estrous towards the end of breeding season which is low in number, it is physiologically more demanding for stags to maintain the breeding status as they could be exhausted from the long rutting season. Therefore, the higher peaks towards the end of breeding season signify more reproductive effort physiologically for the stags. Breeding season of Rusa deer based on the observation begins in April and lasted until August. Hence, 
monitoring testosterone profile in stags can also reflects estrous cyclicity of hinds during the rutting season.

Pattern of semen motility in Rusa deer over six months period in relation to serum concentration level is described in this study. Semen motility was best in July, good in May, acceptable in April and June, poor in September and void of motility in August. Semen motility in Rusa deer showed positive correlation to serum testosterone concentration. From this study, two peaks of serum testosterone concentration similarly follows for peaks in sperm motility during May and July. This testosterone peak signify the best semen motility produced by the stags and probably the peak of rutting season. Testosterone was known to play important role in the production of sperm and development of sexual behavior (Albrizio et al., 2013). Therefore, serum testosterone concentration can be used as an indicator to collect semen, which is in the month of May and July in this study during the peak testosterone concentration.

While it is ideal to encompass meteorological data to breeding seasonality of Rusa deer, this relationship could not be established yet in Rusa deer. Meteorological data (temperature, relative humidity, rainfall) has no significant effect to semen motility and testosterone profile of Rusa deer. This probe more questions to the factors that could the trigger the seasonality in tropical deer as most studies specifically in deer seasonality suggested to investigate the possible linkage of breeding seasonality with meteorological data, especially rainfall (Asher, 2011; Asher et al., 2000; Umapathy et al., 2007). Our findings is in agreement with Sambar deer which has no significant effect of rainy or dry season based on reproductive cyclicity and sexual behaviors (Putranto et al., 2010). Other study in bats in the tropics suggested that while breeding seasonality can easily be understood in short-lived mammals, breeding seasonality of long-lived mammals such as deer is far more complex and multifactorial (O’Brien, 1993). But from the observation, there were two peaks of sperm motility in May and July which is separated by a drier period in June. Therefore, to a certain degree, rainfall could be a rough indicator of breeding seasonality in Rusa deer guided with information from testosterone concentration.

\section{Conclusion}

Breeding seasonality of Rusa deer partly still remains unresolved, but can partially be elucidated by the serum testosterone concentration together with sperm motility. Meteorological data such as temperature, relative humidity and rainfall alone are insufficient to determine the breeding seasonality in Rusa deer. However, it was observed that after the dry period in June, semen motility peaked rapidly to its maximum in July. Although it is untimely to make a statement based on a single observation, this findings in terms of management is crucial in preparing the male breeders for assisted breeding purpose. Rusa deer stags is reproductively active from April to July, low in August and starts to rise again in September. In conclusion, testosterone serum concentration level during the month of May and July is the best time to collect semen for assisted reproductive technology such as artificial insemination.

\section{Acknowledgement}

The authors wish to thank the staff of the Universiti Putra Malaysia (UPM) Deer Breeding Unit, TPU, Mr. Zulfakarudin Zamri, Mr. Azrul Hisham, Mr Jeeva a/l Krishnan and Ms. Aznida Che Alli for their help with animal restraint during semen collection. We thank Mr. Yap Keng Chee, Mr. Ganesamurthi, Mr Fahmi Mahsuri, Mr Aizad and Mr Faizal for their assistance.

\section{Funding Information}

This research was supported by a grant from Research University Grant Scheme (RUGS), UPM Project 9301400, Universiti Putra Malaysia Grant 2016, GP-IPS/2016/9483300 and Fundamental Research Grant Scheme (FRGS), 07-01-16-1825FR.

\section{Author's Contributions}

All authors contributed equally on the preparation of the manuscripts.

\section{Ethics}

The authors have no conflicting interest for this research.

\section{References}

Albrizio, M., M. Siniscalchi, R. Sasso and A. Quaranta, 2013. Effects of the environment on dog semen parameters and testosterone concentration. Theriogenology, 80: 800-804.

DOI: $10.1016 / \mathrm{j}$.theriogenology.2013.07.005

Amare, E., H. Wahid, Y.Z.Z. Zahari, M. Felix and A. Mathew et al., 2009. Effects of cryopreservation on sperm head morphometric dimensions of barking deer (Muntjac) spermatozoa. Proceedings of the Annual MSAP Conference, Jun. 2-5, Kola Kinabalu, pp: 47-48.

Asher, G.W., 2011. Reproductive cycles of deer. Anim. Reproduct. Sci., 124: 170-175.

DOI: 10.1016/j.anireprosci.2010.08.026

Asher, G.W., D.K. Berg and G. Evans, 2000. Storage of semen and artificial insemination in deer. Anim. Reproduct. Sci., 62: 195-211. DOI: $10.1016 / \mathrm{S} 0378-4320(00) 00159-7$ 
Bartos, L., 2012. Endocrine relationships between rankrelated behavior and antler growth in deer. Front. Biosci., E4: 1111-26. DOI: 10.2741/e445

Bronson, F.H., 2009. Climate change and seasonal reproduction in mammals. Philosophical Trans. Royal Society B, Biol. Sci., 364: 3331-3340. DOI: $10.1098 /$ rstb.2009.0140

Hedges, S., J.W. Duckworth, R. Timmins, G. Semiadi and G. Dryden, 2015. Rusa timorensis, javan Deer. DOI: 10.2305/IUCN.UK.20152.RLTS.T41789A22156866.en

Iswadi, M.I., Z.F. Ann, M.M. Hafiz, M.D. Hafiz and F.J. Fahrul et al., 2012. Collection, analysis and cryopreservation of semen from Malayan gaur (Bos gaurus hubbacki): A preliminary study. Open Vet. J., 2: 109-114.

Kawanishi, K., D.M. Rayan, M.T. Gumal and C.R. Shepherd, 2014. Extinction process of the sambar in Peninsular Malaysia. Deer Specialist Group Newslett., 26: 48-59.

Li, C., R.P. Littlejohn, I.D. Corson and J.M. Suttie, 2003. Effects of testosterone on pedicle formation and its transformation to antler in castrated male, freemartin and normal female red deer (Cervus elaphus). General Comparat. Endocrinol., 131: 21-31. DOI: 10.1016/S0016-6480(02)00625-1

Mahre, M.B., H. Wahid, Y. Rosnina, C.A. Azlan and F.F.A. Jesse, 2012. Exfoliative vaginal cytology during the oestrous cycle of Rusa deer (Cervus timorensis). Proceedings of the International Conference on One Health and 24th VAM Congress, Sept. 21-23, Marriott Putraja, pp: 345-346.

DOI: $10.13140 /$ RG.2.1.1044.8802

Mahre, M.B., H. Wahid, Y. Rosnina, F.F. Jesse and A.Z. Jaji et al., 2016. Anatomy of the female reproductive system of Rusa deer (Rusa timorensis). Sokoto J. Vet. Sci., 14: 15-20. DOI: 10.4314/sokjvs.v14i1.3

Mahre, M.B., H. Wahid, Y. Rosnina and F.F.A. Jesse, 2015a. Assessment of temperament in Rusa timorensis and its relationship to stress. Am. Society Anim. Sci., 93: 1276-1283.

DOI: $10.2527 /$ jas.2014-8080

Mahre, M.B., H. Wahid, Y. Rosnina and F.F.A. Jesse, $2015 \mathrm{~b}$. Estrus response and pregnancy rate of Rusa timorensis following estrus synchronization with prostaglandin analogue. Malaysian Society Anim. Product., 18: 45-53.

Mahre, M.B., H. Wahid, Y. Rosnina, F.F.A. Jesse and C.A. Azlan et al., 2014. Sperm attributes and morphology on Rusa timorensis: Light and scanning electron microscopy. Anim. Reproduct. Sci., 148: 245-250. DOI: 10.1016/j.anireprosci.2014.06.006

Mohd-Khan, M.K., 1967. Population trends of deer in Perak as seen in licensees report. Malaysian Natural J.
Mourik, S.V. and T. Stelmasiak, 1990. Endocrine Mechanisms and Antler Cycles in Rusa Deer, Cervus (Rusa) timorensis. In: Horns, Pronghorns and Antlers: Evolution, Morphology, Physiology and Social Significance, Bubenik, G.A. and A.B. Bubenik (Eds.), Springer Science and Business Media, New York, ISBN-10: 1461389666, pp: 416-425.

Moyes, K., D.H. Nussey, M.N. Clements, F.E. Guinness and A. Morris et al., 2011. Advancing breeding phenology in response to environmental change in a wild red deer population. Global Change Biol., 17: 2455-2469. DOI: 10.1111/j.1365-2486.2010.02382.x

O'Brien, G.M., 1993. Seasonal reproduction in flying foxes, reviewed in the context of other tropical mammals. Reproduct., Fertility Dev.., 5: 499-521. DOI: $10.1071 /$ RD9930499

Pavitt, A.T., C.A. Walling, E. Möstl, J.M. Pemberton and L.E.B. Kruuk, 2015. Cortisol but not testosterone is repeatable and varies with reproductive effort in wild red deer stags. General Comparat. Endocrinol., 222: 62-68. DOI: 10.1016/j.ygcen.2015.07.009

Pintus, E. and J.L. Ros-Santaella, 2014. Assisted reproductive technologies in deer. Scientia Agric. Bohemica, 45: 136-146.

Putranto, H.D., E. Soetrisno, Nurmeiliasari, A. Zueni and B. Gibson, 2010. Recognition of seasonal effect on captive Sumatran Sambar deer reproductive cyclicity and sexual behaviors. Biodiversitas, 11: 200-203. DOI: 10.13057/biodiv/d1 10406

Samsudewa, D. and S.S. Capitan, 2013. Reproductive behaviour of timor deer (Rusa Timorensis). Wartazoa, 21: 108-113. DOI: 10.14334/wartazoa.v21i3.976

Sarsaifi, K., J. Vejayan, A. Wahid Haron, R. Yusoff and H. Hani et al., 2015. Protein profile and functionality of spermatozoa from two semen collection methods in Bali bulls. Livestock Sci., 172: 96-105. DOI: 10.1016/j.livsci.2014.12.004

Savanth, V.V. and P.C. Saseendran, 2012. Impact of testosterone on the antler stages in sambar deer (Rusa unicolor) stags. Tamilnadu J. Vet. Anim. Sci., 8: 279-285.

Sinclair, S.E. and K.B. Woodford, 2000. Tropical/SubTropical Deer Farming in Australia. In: An Overview of Sub-Tropical and Tropical Deer Production, Dryden, G.M. (Ed.), pp: 62-62.

Umapathy, G., S.D. Sontakke, A. Reddy and S. Shivaji, 2007. Seasonal variations in semen characteristics, semen cryopreservation, estrus synchronization and successful artificial insemination in the spotted deer (Axis axis). Theriogenology, 67: 1371-1378. DOI: 10.1016/j.theriogenology.2007.01.019

Vidyadaran, M.K., M. Jaafar and J. Ibrahim, 1993. The Deer Industry in Malaysia. In: The Animal Industry in Malaysia, Fatimah, C.T.N.I., A.H. Ramlah and A.R. Bahaman (Eds.), Faculty of Veterinary Medicine and Animal Science, Universiti Pertanian Malaysia, Serdang, ISBN-10: 9679600394, pp: 111-119. 
Villagrán, M. and R. Ungerfeld, 2013. Permanent contact with females increases testosterone and improves fresh semen traits in pampas deer (Ozotoceros bezoarticus) males. Anim. Reproduct. Sci., 143: 85-90. PMID: 24220343

Wahid, H., Y. Ming and Z.Z. Zainal, 2000. Evaluation of semen collected by electroejaculation from captive lesser Malay chevrotain (Tragulus javanicus). Am. Assoc. Zoo Vet., 31: 164-167. PMID: 10982126
Zakaria, M.A., M. Zamri-Saad, A.H. Hasliza and H. Wahid, 2016. Growth and reproductive performances of farmed timorensis deer, Cervustimorensis. Pertanika J. Trop. Agric. Sci., 39: 79-86.

Zerbe, P., M. Clauss, D. Codron, L. Bingaman Lackey and E. Rensch et al., 2012. Reproductive seasonality in captive wild ruminants: Implications for biogeographical adaptation, photoperiodic control and life history. Biol. Rev., 87: 965-990. PMID: 22780447 